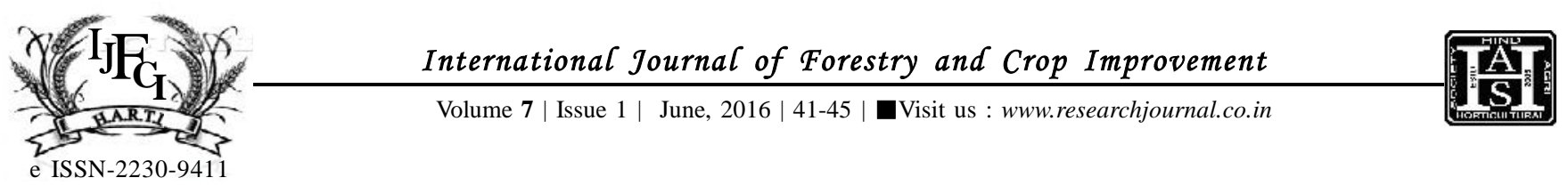

RESEARCH ARTICLE

DOI: $10.15740 / \mathrm{HAS} / \mathrm{IJFCI} / 7.1 / 41-45$

\title{
Development and performance verification of soil testing kit
}

\author{
G. R. RAJAKUMAR AND S.V. PATIL
}

\begin{abstract}
It was planned to produce a kit by the authors at KVK, Sirsi, UAS, Dharwad during 2009-10. The so developed 'Om kit-Part-I' was released in Krishimela 2010 of UAS, Dharwad. Trials have been conducted during 2009-10, 2010-11 and 2011-12 at KVK, Sirsi (Uttar Kannada district) and during 2011-12 and 2012-13 at KVK, Hanumanamatti (Haveri district). Universal indicator is also available in the market as a ready product. Hence, production of such liquid was tried with available indicators suitable for specific ranges. The combinations were tried. The result is the DHUN indicator. The production of equipment was tried with available electrical devices with standard EC solutions suitable for specific ranges. The combinations were tried. The result is the SLIM stick. The salinity measurement is through this SLIM stick (Salinity Light Intensity Monitor stick). Ranjan Kumar Basak's soil testing methods were modified and brought into this kit method which clearly indicates the per cent of organic matter in soil very easily and quickly. It gives colour development (Orange yellow, olive green and bluish green for low, medium and high organic matter levels).
\end{abstract}

KEY WORDS : Soil testing kit, pH indicator, Salinity, Organic C

How TO CITE THIS ARTICLE : Rajakumar, G.R. and Patil, S.V. (2016). Development and performance verification of soil testing kit. Internat. J. Forestry \& Crop Improv., 7 (1) : 41-45, DOI: 10.15740/HAS/IJFCI/7.1/41-45.

Article Chronical : Received : 09.03.2016; Revised : 10.04.2016; Accepted : 11.05.2016

Address of the Correspondence : S.V. PATIL, Regional Horticultural Research and Extension Centre, U.H.S. Campus, G.K.V.K., Post BENGALURU (KARNATAKA) INDIA Email: sangappavpatil@gmail.com

Address of the Coopted Authors : G. R. RAJAKUMAR, Department of Natural Resources Management, College of Forestry (U.A.S.) Sirsi, UTTAR KANNADA (KARNATAKA) INDIA $\quad$ Email: rajkumargr@uasd.in 